\title{
The Illusionary Decline in Workforce Quality
}

Joel Best

Published online: 19 January 2012

(C) Springer Science+Business Media, LLC 2012

Consider this excerpt from a 2010 public-radio talk show:

SOCIOLOGY PROFESSOR (the guest on the show): Men 25-34 are less likely to go on to some form of postsecondary education than probably their grandparents and parents did. ... The percentage of men with some form of post-secondary education $25-34$ is actually lower than the percentage of men who had some form of post-secondary education who are 55-64....

PROGRAM HOST: Are you surprised by that, that young men 25-34 are going to be less likely to have postsecondary education than their parents, grandparents?

SOCIOLOGY PROFESSOR: I'm quite surprised by it, and I really don't have a good explanation for it.

The claim that young Americans are less well-educated than their elders has been repeated by a variety of commentators. A 2010 article in Newsweek worried: "The graduation rate among 25 - to 34-year-olds is no better than the rate for the 55- to 64-year-olds who were going to college more than 30 years ago." This decline in educational attainment was the centerpiece of Jacob Funk Kirkegaard's 2007 book, The Accelerating Decline in America's High-Skilled Workforce. Kirkegaard's book seems to have influenced other professors and pundits. David Brooks, for example, picked up the theme in one of his 2008 New York Times columns "As well-educated

\section{J. Best $(\square)$}

Department of Sociology \& Criminal Justice, University of Delaware, 25 Amstel Avenue, Newark, DE 19716, USA

e-mail: joelbest@udel.edu baby boomers retire over the next decades, the quality of the American work force is likely to decline."

To be clear, discussions about the "quality of the workforce" do not refer to workers' dedication, loyalty, or work ethic; the people who write about workforce quality define it simply as years of schooling. That is, a more educated workforce is considered more highly-skilled, of higher quality. If young people are getting less schooling than previous generations, this would, by definition be proof that workforce quality is declining.

On the one hand, statistics about declining educational attainment do have a surprising, human-bites-dog quality. Since the end of World War II, there has been a concerted campaign to discourage dropping out of school. And surely most parents press their children to continue their schooling the expectation that each generation should be better educated is a central component in the American Dream. The postwar GI Bill, the student loan program, and other federal policies have sought to open opportunities for higher education. Is it possible that, in the face of all of these efforts to promote schooling, education attainment is actually going down?

Well, no.

The worried declarations that American educational attainment and, therefore, workforce quality are in decline reflect a misinterpretation of the data. These data come from the Census Bureau's Current Population Survey. Each year, the CPS reports on the educational attainment of the population, ages 25 and above. These are the data on which Kirkegaard relied. He presents a graph using data from the 2006 survey that, he says, show that: "American residents aged 25-54 are generally not better educated than their immediately older fellow residents aged $55-59 . .$. " This is an interpretation that ignores several key points. 


\section{Levels of Schooling Continue to Rise}

The first point is so obvious that it hardly deserves mention: American's educational attainment has been rising for decades. Consider Fig. 1, which charts CPS data on the percentages of Americans aged 25 and above who graduated from high school and college (prior to the early 1990s, the CPS measured educational attainment in years of schooling, and I have treated those reported as having 4 years of high school as high school graduates, and those with 4 or more years of college as college graduates). The graph is quite clear, from 1940 to 2010, the percentages of both high school graduates and college graduates increased consistently and dramatically. This is hardly news; most people are aware of these trends. But it does raise the question: if more people are completing high school and college, how could educational attainment be declining?

\section{People Continue Going to School}

The second point may be a bit less obvious. It is easy to assume that there is a standard pathway through the

\section{Percentages of High School and College Graduates among Persons 25 Years Old and Older, 1940-2010}

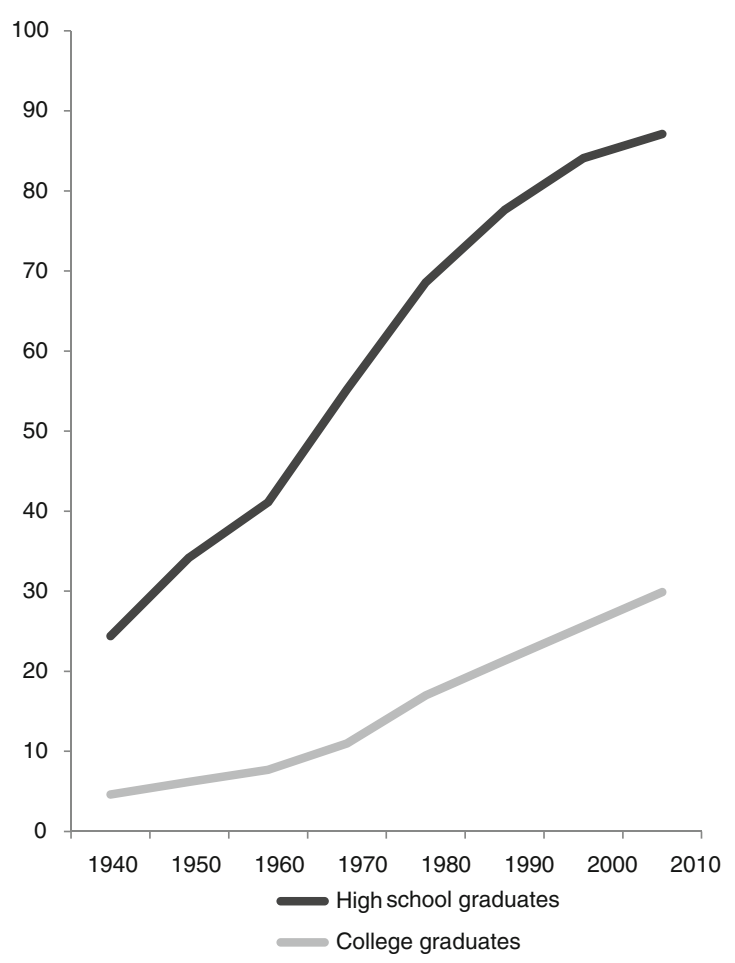

Fig. 1 Percentages of high school and college graduates among persons 25 years old and older, 1940-2010
American educational system: a young person stays in school and graduates from high school (at, say, age 18), enters college the following fall and graduates 4 years later (age 22), and perhaps goes on to enter graduate or professional school. This is, if you will, the fast track, and lots of people take it. It's what I did. We might suspect that most of the commentators who write essays about the declining quality of the workforce took exactly that path.

But there are other routes to an education. People interrupt their schooling for all sorts of reasons: they enter the military; they find that work obligations or family responsibilities interfere with their ability to stay in school; they leave school and then return to acquire new credentials; and so on. The result is that, if we follow a cohort of people across time, we will discover that they inevitably become more educated as the years pass.

We can see this effect in Fig. 2a. It tracks three levels of higher education among the cohort of people who were 2529 in 1995, through 2010 (when they were 40-44). In other words, this measures the same cohort through 4 different years - 1995, 2000, 2005, and 2010. The bottom line tracks the percentage with at least a master's degree: in 1995, this was $4.5 \%$; this percentage more than doubled by 2010 , when it was $10.9 \%$. This might not seem that surprisingeven people of the fast track might not complete a master's degree by age 25 . But notice that the middle line (the percentage with a bachelor's degree) also rises (from 24.7 to 32.0 percentage), and so does the top line that tracks those with some college (which increases from 54.1 to $58.2 \%$ ). In other words, if we follow the same cohort as it ages, educational attainment climbs.

The same patterns appears in other cohorts. Figure $2 \mathrm{~b}$ finds the same trends in a somewhat older cohort (those aged 35-39 in 1995, and 50-54 in 2010). The increases are less dramatic because most people in their midthirties will have finished their schooling, but the percentages with master's degrees, bachelor's degrees, and some college all rise.

Thus, we see one problem with commentators comparing the educational attainment of those $25-29$ or $25-34$, with the achievements of people near the end of their working lives. Older people have had more time to acquire education. If we track any given cohort, it will be less educated when it enters the workforce than when it leaves.

\section{In General, Successive Cohorts Receive More Education}

My third point is a bit less obvious, but it derives from the first two: because overall American educational attainment has been increasing, each successive cohort tends to have more education at a given age than its predecessors. 
a Percentages Achieving Different

Levels of Higher Education in the Cohort Aged

25-29 in 1995, 1995-2010

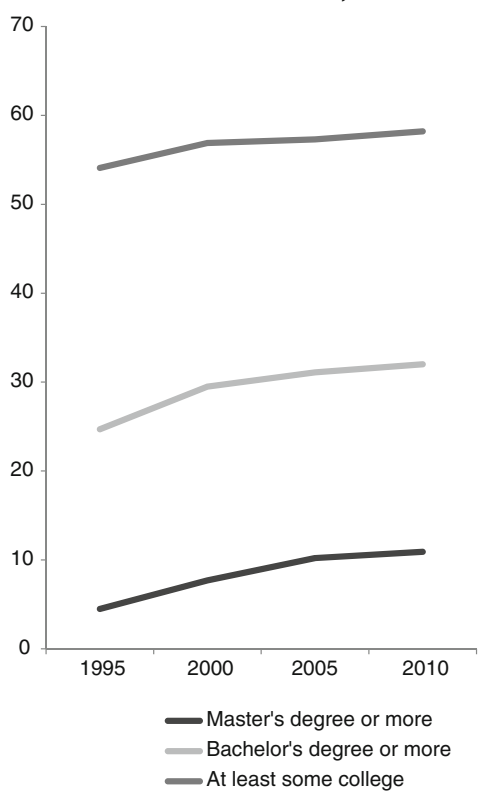

b Percentages Achieving Different Levels of Higher Education in the Cohort Aged 35-39 in 1995, 1995-2010

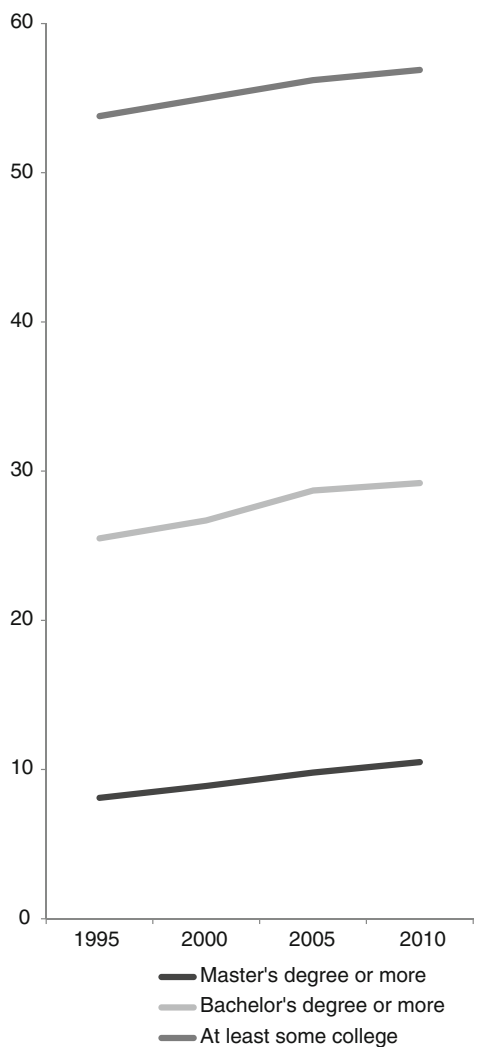

Fig. 2 a Percentages achieving different levels of higher education in the cohort aged 25-29 in 1995, 1995-2010. b Percentages achieving different levels of higher education in the cohort aged 35-39 in 1995, 1995-2010
Percentages of Those Aged 25-29

Achieving Different Levels of Higher Education, 1995-2010

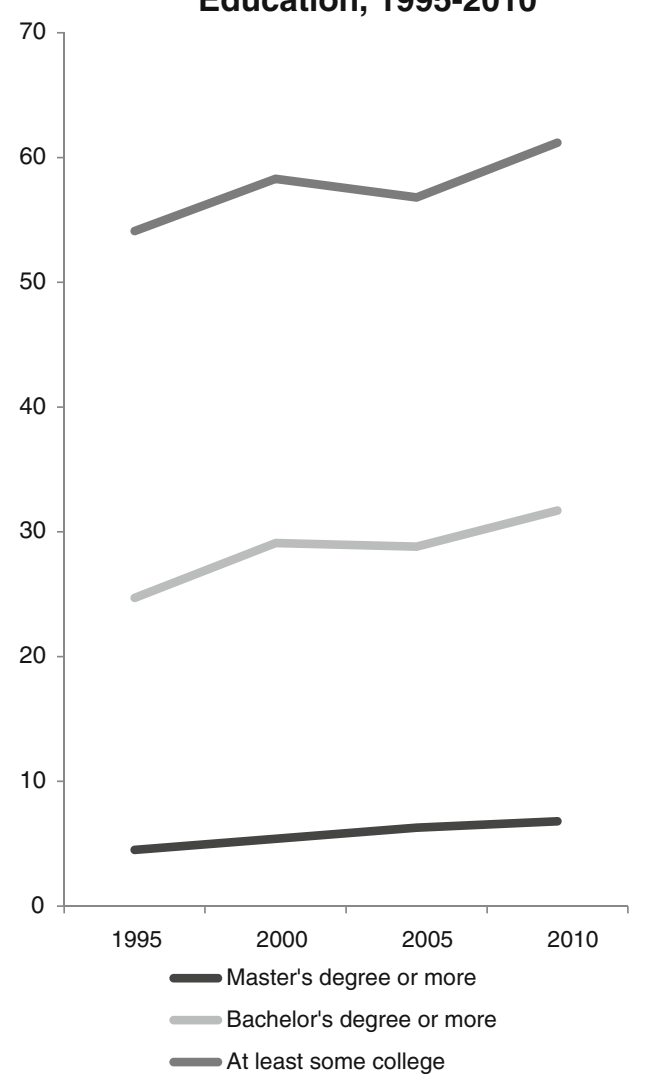

Fig. 3 Percentages of those aged 25-29 achieving different levels of higher education, 1995-2010

Examine Fig. 3. Although it may, at first glance, resemble the two preceding graphs, it displays very different information. Figure $2 \mathrm{a}$ and $\mathrm{b}$ tracked particular cohorts - that is, the same people - as they aged. In contrast, Fig. 3 traces educational attainment in the same age group across time; that is, it compares those who were 25-29 in 1995 with their age counterparts (those 25-29 in 2000, and so on). This graph shows that successive cohorts are usually more educated than their predecessors. In $1995,4.5 \%$ of those aged 25-29 had a master's degree, but $6.8 \%$ of 25-29-year-olds had that level of education in 2010. The same period showed substantial increases in all three measures of higher education attainment. This pattern characterizes most age groups.

So, to recap: overall educational attainment has been increasing; within any given cohort, educational attainment inevitably rises over time; and successive cohorts generally receive more education than their predecessors. If this is true, how could all those commentators conclude that today's young people aren't as well educated as older workers. 


\section{Those "Well-Educated Baby Boomers"}

There is a kernel of truth to the commentators' claims. There is an anomaly in the data when it comes to baby boomers. If we look at those who were 45-49 in 1995 (they would have been born in 1946-50 - the cutting edge of the baby boom), we find that $12.2 \%$ had a master's degree; while only $10.3 \%$ of those in the same age group in 2010 (post-boomers born in 1961-65) had master's degrees. This decline runs counter to the general pattern we've observed. What accounts for the boomer's fabulous educational attainment?

Figure 4 can help us understand what happened. It uses the CPS for 1995, a year that lets us compare educational attainment among pre-boomers, boomers, and postboomers. The graph presents the percentages of males and females in different age groups who had at least some college. Among women, the percentage who had been to college increased in each successive cohort - exactly what me might expect as obstacles to women entering higher education declined.

But perhaps the most striking feature of Fig. 4 is that educational attainment peaked among men who were 45-49 in 1995: fully $60.4 \%$ of these men had some college experience; half of those- $30.2 \%$ - earned bachelor's degrees. This is a strikingly high level of educational attainment. When the commentators say that young people aren't as

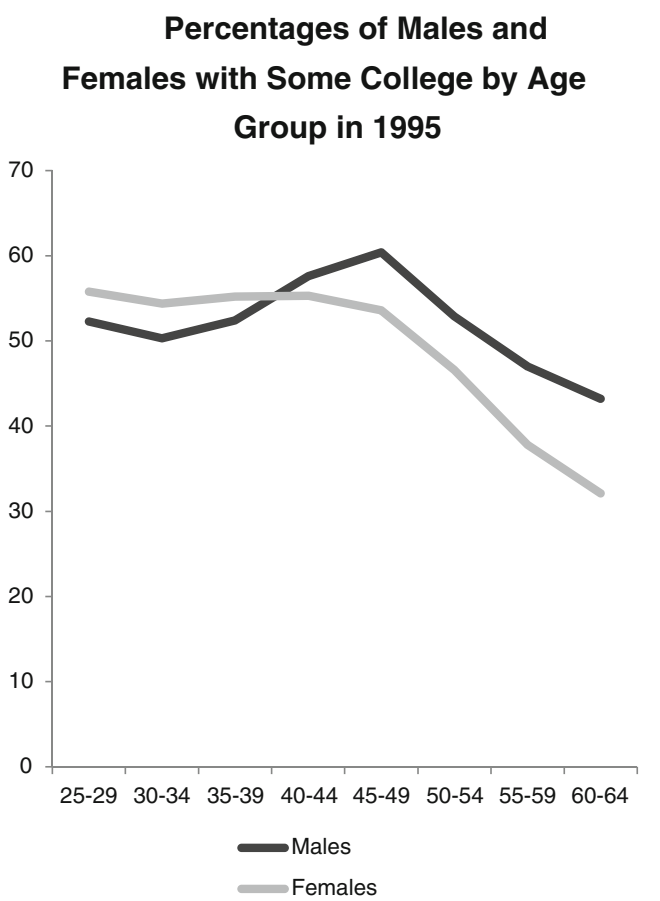

Fig. 4 Percentages of males and females with some college by age group in 1995 educated as older workers, these are the folks they mean. So why did men aged 45-49 attain unusually high levels of education? They were born in 1946-49, at the front end of the baby boom. To be sure, they were the first children exposed to television and rock and roll. But, there was another, more compelling circumstance that shaped their educational lives.

These males turned 18 between 1964 and 1968. That meant they became eligible for the draft at precisely the time when the war in Vietnam expanded most rapidly. College students were eligible for draft deferments, and these men-more than their counterparts who were 5 or 10 years older or younger-found themselves pursuing higher education. The draft encouraged early baby boomer males to enter college at unusually high rates. For some of them, being deferred was probably more important than becoming well-educated.

\section{The Appeal of Talking About a Declining Workforce}

The claim that today's young people aren't receiving as much education as their predecessors taps into our anxieties about slackers, failing schools, and the "dumbest generation." The notion that young workers are less well qualified than their older counterparts is one of those factoids that has broad appeal. Conservatives view this evidence of educational decline as proof that American education needs reform, that we need standardized tests to evaluate whether teachers and schools are effective, as well as vouchers to allow students to escape from weak public schools. Liberal commentators find the claim no less compelling, because it suggests that the government should increase support for higher education and workforce training programs.

But the evidence doesn't really support a general narrative of educational decline: in fact, each year, people of a given age are a bit more educated than those in the preceding cohort, and with each passing year, every cohort becomes better educated. Things are, in short, getting steadily better. Of course we might wish that they were better yet, that every American received extensive education, so that no adult would be left behind. Happily, we know how to make things better: history tells us exactly what works, exactly how to maximize educational attainment. Forget vouchers or work training programs, and reinstate the draft with educational deferments.

Joel Best was born in 1946, he received educational and occupational deferments. He is a senior editor of Society and teaches at the University of Delaware. 